\title{
Characterization of Modified and Polymer Coated Alumina Surfaces by Infrared Spectroscopy
}

\author{
Ashraf Yehia El-Naggar ${ }^{1,2}$ \\ ${ }^{1}$ Egyptian Petroleum Research Institute, Nasr City, Cairo, Egypt \\ ${ }^{2}$ Chemistry Department, Science Faculty, Taif University, P.O. Box 888, Al-Haweiah, Taif 21974, Saudi Arabia \\ Correspondence should be addressed to Ashraf Yehia El-Naggar; aynaggar361@yahoo.com
}

Received 10 May 2013; Revised 13 August 2013; Accepted 19 August 2013

Academic Editor: Christoph Krafft

Copyright (c) 2013 Ashraf Yehia El-Naggar. This is an open access article distributed under the Creative Commons Attribution License, which permits unrestricted use, distribution, and reproduction in any medium, provided the original work is properly cited.

\begin{abstract}
The prepared, modified, and coated alumina surfaces were characterized by infrared spectroscopy (FTIR) to investigate the surface properties of the individual and double modified samples. FTIR helps in reporting the changes occurred in hydroxyl groups as well as the structure changes as a result of thermal treating, hydrothermal treating, silylation treating, alkali metal treating, coating, and bonding with polymer. FTIR spectroscopy represents the strength and abundance of surface acidic $\mathrm{OH}$ which determine the adsorption properties of polar and nonpolar sorbents. Generally, all treated samples exhibit decrease of OH groups compared with those of parent ones producing alumina surfaces of different adsorptive powers.
\end{abstract}

\section{Introduction}

Infrared spectroscopy has been successfully used to clarify the structure of aluminum with other solutes and to characterize the modification and coating reactions proceeding on the alumina surfaces. DRIFT spectra permit better understanding of the reactions and the properties of the untreated, monotreated, double-treatment modified, coated, and bonded samples in addition to the double modification. Alumina is successively studied by Naito and Takei [1] as a large specific surface area solid support; a model for the liquid phase distribution is covered with two different types of liquid films, a monolayer and a bulk liquid layer, depending on liquid loading. Continuously, quantitative interpretation of the solute retention in a nonpolar solute and polar liquid stationary phase (Triton X-100) which was coated on alumina with different loading was studied and compared with reference support (chromosorb P) [2]. The different modification methods of alumina are very important to produce high chance of various alumina surfaces to increase its uses as adsorbents, solid support, and stationary phases in chromatographic science and, also, to cover the separation of different chromatographic problems. The selection of infrared spectroscopy for characterizing the modified alumina surfaces is important to follow the change in the surface hydroxyl groups of alumina brought from the different modification methods.

One of the great attractions of the use of alumina support for chromatographic columns is the ease by which its surface can be modified with different groups or polymers by reaction with the silanol groups. There are two types of modifications: the first one is physical modification [3] like thermal, hydrothermal, and irradiation treatments which leads to the change in the concentration and ratio of silanol and siloxane groups on the surface in case of silica and also a more change of the pore size distribution than a chemical modification; the second is chemical modification like the formation of covalent bonds (by alkylsilanes, etc.) with silanol groups at the surface and also like coating with high molecular compounds [4]; this type significantly changes adsorption properties of the silica surface.

The main purpose of alumina surface modification is shielding the active hydroxyl groups, active sites, and attachment to the accessible adsorbent surface organic ligands and 
chromatographic support which are responsible for specific surface interactions.

\section{Experimental}

2.1. Preparation of Alumina [5]. Alumina (aluminum hydroxide gel) was precipitated from a solution of $25 \% \mathrm{wt} / \mathrm{v}$ $\mathrm{Al}_{2}\left(\mathrm{SO}_{4}\right)_{3} \cdot 18 \mathrm{H}_{2} \mathrm{O}$. Precipitation was made using ammonia solution of $\mathrm{pH}=12$, and the precipitation $\mathrm{pH}$ was adjusted at 8.6. The alumina preparation was done according to DeBore method and the recent modified method [3,5]. After complete precipitation the gel was stirred for $30 \mathrm{~min}$, aged at $90^{\circ} \mathrm{C}$ for $24 \mathrm{hr}$, washed with deionized water until free from sulphate, and dried at $120^{\circ} \mathrm{C}$ till constant weight. The dried alumina sample was then crushed and sieved to 60-80 meshes. The concentration of $\mathrm{OH}^{-}$is decided by the $\mathrm{pH}$ value of the precipitation reagent, which is adjusted by ammonia water.

The properties of alumina depend to a great extent on the precursor used in their preparation, precipitating agent, condition of preparation, drying, calcinations temperature, and many others. For this reason, one alumina batch was only used throughout this investigation.

\subsection{Modification Methods}

2.2.1. Calcination [4]. Alumina sample was calcined in a muffle furnace at $500^{\circ} \mathrm{C}$ for $16 \mathrm{hr}$ and at $1000^{\circ} \mathrm{C}$ for $5 \mathrm{~h}$ to stabilize the number and type of active sites.

2.2.2. Hydrothermal Treatment [6-8]. The hydrothermal treatment was carried out for parent and calcined samples; $15 \mathrm{gm}$ of sample and $50 \mathrm{~mL}$ of deionized water were placed into stainless steel autoclave at $220^{\circ} \mathrm{C}$ and 15 bar for $24 \mathrm{~h}$. The autoclave was sealed and deaerated by flushing with nitrogen gas several times. The hydrothermally treated silica was subjected to acid washing by $\mathrm{HCl}$ to remove any trace cations which may be occluded on the surface of silica.

2.2.3. Silylation Using Dimethyldichlorosilane [9-11]. The method used for preparing the silylating samples was the same as that described earlier; the sample was refluxed in a Soxhlet by $30 \mathrm{vol} \%$ of dimethyldichlorosilane in toluene for $6 \mathrm{~h}$. Then, the sample was removed from the Soxhlet, washed by deionized water, and dried at $120^{\circ} \mathrm{C}$ overnight.

2.2.4. Treating with Alkali Metal [12, 13]. The modification of the surface properties of alumina with alkali metal chloride $(\mathrm{NaCl})$ is described for parent and calcined samples dependent on a $10 \%$ salt loading. This was performed by evaporating $30 \mathrm{ml}$ of a solution containing $15 \mathrm{~g}$ of the alumina samples and $1.67 \mathrm{~g}$ of $\mathrm{NaCl}$ on a water-bath with occasional stirring. This salt-coated alumina was dried for $3 \mathrm{~h}$ at $120^{\circ} \mathrm{C}$ and then heated at $750^{\circ} \mathrm{C}$ for $2 \mathrm{~h}$. The same procedure was followed for silica sample.
TABLE 1: Notation of the prepared samples.

\begin{tabular}{ll}
\hline Notation & Treatments \\
\hline $\mathrm{Al}$ & Parent alumina (60-80 mesh) \\
$\mathrm{Al}_{\mathrm{C} 500}$ & Alumina calcined at $500^{\circ} \mathrm{C}$ \\
$\mathrm{Al}_{\mathrm{C} 1000}$ & Alumina calcined at $1000^{\circ} \mathrm{C}$ \\
$\mathrm{Al}_{\mathrm{HT}}$ & Hydrothermally treated alumina \\
$\mathrm{Al}_{\mathrm{CHT}}$ & Hydrothermally treated pre calcined alumina \\
$\mathrm{Al}_{\mathrm{Na} 10 \%}$ & Alumina coating with $\mathrm{NaCl}$ and then calcined at $700^{\circ} \mathrm{C}$ \\
$\mathrm{Al}_{\mathrm{CNa} 10 \%}$ & $\begin{array}{l}\text { Calcined alumina coating with } \mathrm{NaCl} \text { and then calcined } \\
\mathrm{Al}_{\mathrm{CCo10} \%} \mathrm{C}\end{array}$ \\
$\mathrm{Al}_{\mathrm{CBo10} \%}$ Calcined alumina coating by $10 \%$ of polyethyleneglycol \\
& polyethyleneglycol \\
\hline
\end{tabular}

\subsubsection{Treatment with Polymers}

(a) Coating with Polyethyleneglycol (PEG) [14, 15]. A stationary phase used for this purpose was Carbowax $20 \mathrm{M}$ (polyethyleneglycol) having high molecular weight. Parent and $1000^{\circ} \mathrm{C}$ calcined silica samples were coated with loading with 25 and $10 \%$ of the stationary phase, respectively, while both parent and $1000^{\circ} \mathrm{C}$ calcined alumina samples were coated with loading with $10 \%$. The polymer was dissolved in a proper amount of chloroform and added to the sample. The mixture was heated in rotary evaporator till the complete evaporation of the chloroform. The coated sample was then dried at $120^{\circ} \mathrm{C}$ for $24 \mathrm{~h}$.

(b) Bonding with Polyethyleneglycol (PEG) $[16,17]$. The above mentioned coated samples were transferred to a $50 \mathrm{~mL}$ volumetric pipette containing a glass wool plug at the restricted end. The pipette was hold at a flow of nitrogen $200 \mathrm{ml} \mathrm{min}^{-1}$ for at least $30 \mathrm{~min}$ and reduced to $5 \mathrm{ml} \mathrm{min}^{-1}$. Then the temperature was raised to $270^{\circ} \mathrm{C}$ over a period of about $2 \mathrm{~h}$ and maintained at that temperature for $20 \mathrm{~h}$ before cooling to room temperature. The supports were then transferred to a Soxhlet and successively extracted with dichloromethane and methanol for three weeks to remove all unbound polymer.

The prepared and modified alumina samples and their notation were given in Table 1.

2.3. Fourier Transforms Infrared Spectroscopy (FTIR). Infrared spectroscopic analysis (FTIR) was carried out to characterize the main constituents of the prepared samples using FTIR-Perkin Elmer-Spectrum-I, Supplied with Selector Diffuse Reflectance (Specac), and Environmental Chamber (Specac). An empty chamber was used as infrared background, and the backgrounds due to moisture and carbon dioxide were subtracted automatically from infrared spectra of alumina when alumina samples were placed in the DRIFTS chamber.

The samples were examined under vacuum at $150^{\circ} \mathrm{C}$. The sample percent with $\mathrm{KBr}$ powder was kept constant $(5 \% \mathrm{wt} / \mathrm{wt})$. Workbench spectra were recorded from 5000 to $600 \mathrm{~cm}^{-1}$. For each sample, 32 scans were accumulated at a spectral resolution of $4 \mathrm{~cm}^{-1}$. The absorbance was reflected 
TABLE 2: DRIFT bands that are characterizing parent and thermally treated alumina samples.

\begin{tabular}{|c|c|c|c|c|}
\hline \multirow{2}{*}{$\begin{array}{l}\text { Bands } \\
\mathrm{cm}^{-1}\end{array}$} & \multirow{2}{*}{ Assignment } & \multicolumn{3}{|c|}{ Absorbance } \\
\hline & & $\mathrm{Al}$ & $\mathrm{Al}_{\mathrm{C} 500}$ & $\mathrm{Al}_{\mathrm{C} 1000}$ \\
\hline 3504 & The wide band corresponds to & - & 0.4 & 0.24 \\
\hline 3334 & $\begin{array}{l}\text { the hydroxyl groups adsorbed on } \\
\text { the surface (for free } \mathrm{Al}_{2} \mathrm{O}_{3} \text { ) }\end{array}$ & 0.55 & - & - \\
\hline 1633 & $\begin{array}{l}\text { Band corresponds to the bending } \\
\text { of the } \mathrm{H}-\mathrm{O}-\mathrm{H} \text { bonds }\end{array}$ & 0.31 & 0.25 & 0.15 \\
\hline 1157 & & 0.47 & 0.37 & 0.2 \\
\hline 1058 & $\begin{array}{l}\text { Cluster of } \mathrm{Al}^{3+} \text { and } \mathrm{O}^{2-} \text { ions on } \\
\text { the surface of alumina }\end{array}$ & 0.56 & 0.37 & - \\
\hline 877 & & 0.54 & 0.51 & - \\
\hline 754 & $\mathrm{Al}-\mathrm{O}$ overtone & - & - & 0.51 \\
\hline 671 & & 0.65 & 0.56 & 0.52 \\
\hline
\end{tabular}

TABLE 3: DRIFT bands that are characterizing alkali metal treated alumina samples.

\begin{tabular}{|c|c|c|c|}
\hline \multirow{2}{*}{$\begin{array}{l}\text { Bands } \\
\mathrm{cm}^{-1}\end{array}$} & \multirow{2}{*}{ Assignment } & \multicolumn{2}{|c|}{ Absorbance } \\
\hline & & $\mathrm{Al}_{\mathrm{Na}}$ & $\mathrm{Al}_{\mathrm{CNa}}$ \\
\hline 3566 & $\begin{array}{l}\text { The hydroxyl groups adsorbed on the } \\
\text { surface (for free } \mathrm{Al}_{2} \mathrm{O}_{3} \text { ) }\end{array}$ & 0.38 & 0.31 \\
\hline 1636 & Bending of the $\mathrm{H}-\mathrm{O}-\mathrm{H}$ bonds & 0.26 & 0.18 \\
\hline 1053 & $\begin{array}{l}\text { Cluster of } \mathrm{Al}^{3+} \text { and } \mathrm{O}^{2-} \text { ions on the surface } \\
\text { of alumina }\end{array}$ & 0.36 & 0.31 \\
\hline 856 & & 0.47 & 0.59 \\
\hline 727 & Al-O stretching & 0.5 & 0.6 \\
\hline 653 & & 0.5 & 0.6 \\
\hline
\end{tabular}

as a change in hydroxyl groups due to the modification methods, and these hydroxyl groups appeared in both IR peak height and shift in wave number.

\section{Results and Discussions}

Figures 1-4 show representative DRIFT spectra for parent and modified alumina samples; the data is illustrated in Tables 2-5. Parent alumina sample in (Figure 1(a)) shows broad band at $3334 \mathrm{~cm}^{-1}$ corresponding to the hydroxyl groups stretching on the alumina surface. The band at $1633 \mathrm{~cm}^{-1}$ arises due to the presence of moisture in the sample. Bands in the range of $877-670 \mathrm{~cm}^{-1}$ are ascribed to the Al-O stretching frequency [18].

Comparison of the DRIFT patterns of $\mathrm{Al}_{\mathrm{C} 500}$ and $\mathrm{Al}_{\mathrm{C} 1000}$ with that of $\mathrm{Al}$ as shown in Figure 1 and illustrated in Table 2 indicates that band at $3334 \mathrm{~cm}^{-1}$ assigned to hydroxyl groups adsorbed on the surface shifted to $3504 \mathrm{~cm}^{-1}$ and decrease in its intensity as the calcination temperature increases which is attributed to partial dehydroxylation. The intensity of $1640 \mathrm{~cm}^{-1}$ band also decreases with the increase of the calcination temperature due to removal of physisorbed water. Figure 2 shows the spectrograms of $\mathrm{Al}_{\mathrm{Na}}$ and $\mathrm{Al}_{\mathrm{CNa}}$, respectively. Table 3 lists the bands, band location, and band assignment when these spectrograms are compared with that
TABLE 4: DRIFT bands that are characterizing hydrothermally treated alumina samples.

\begin{tabular}{|c|c|c|c|}
\hline \multirow{2}{*}{$\begin{array}{l}\text { Bands } \\
\mathrm{cm}^{-1}\end{array}$} & \multirow{2}{*}{ Assignment } & \multicolumn{2}{|c|}{ Absorbance } \\
\hline & & $\mathrm{Al}_{\mathrm{HT}}$ & $\mathrm{Al}_{\mathrm{CHT}}$ \\
\hline 3309 & \multirow{2}{*}{$\begin{array}{l}\text { Hydroxyl groups adsorbed on the surface } \\
\text { (for free } \mathrm{Al}_{2} \mathrm{O}_{3} \text { ) }\end{array}$} & 0.87 & 0.75 \\
\hline 3114 & & 0.83 & 0.73 \\
\hline 1557 & Bending of the $\mathrm{H}-\mathrm{O}-\mathrm{H}$ bonds & 0.33 & 0.28 \\
\hline 1060 & $\begin{array}{l}\text { Cluster of } \mathrm{Al}^{3+} \text { and } \mathrm{O}^{2-} \text { ions on the surface } \\
\text { of alumina }\end{array}$ & 0.97 & 0.81 \\
\hline 739 & \multirow{2}{*}{$\mathrm{Al}-\mathrm{O}$ stretching } & 0.98 & 0.84 \\
\hline 664 & & 1 & 0.85 \\
\hline
\end{tabular}

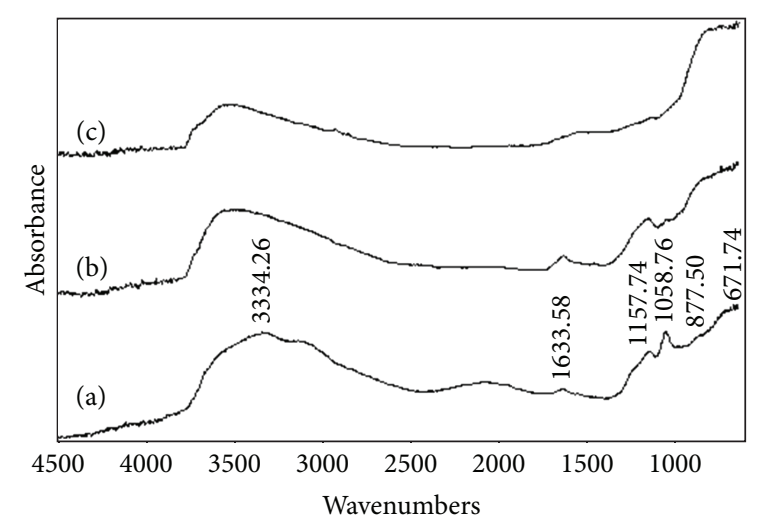

FIGURE 1: DRIFT spectra of (a) $\mathrm{Al}$, (b) $\mathrm{Al}_{\mathrm{C} 500}$, and (c) $\mathrm{Al}_{\mathrm{C} 1000}$.

TABLE 5: DRIFT bands that are characterizing coated and bonded alumina samples.

\begin{tabular}{llcc}
\hline $\begin{array}{l}\text { Bands } \\
\mathrm{cm}^{-1}\end{array}$ & Assignment & \multicolumn{2}{c}{ Absorbance } \\
\hline 3467 & $\begin{array}{l}\text { Hydroxyl groups adsorbed on the } \\
\text { surface }\end{array}$ & 0.17 & 0.3 \\
2942 & $\mathrm{CH}_{2}$ symmetrical stretching & 0.12 & 0.25 \\
2877 & vibrations & 0.13 & 0.24 \\
1729 & Polyethylene glycol (PEG) & 0.1 & 0.2 \\
1616 & Bending of the H-O-H bonds & 0.09 & 0.18 \\
1460 & In-plane scissoring of CH $\mathrm{CH}_{2}$ group & 0.02 & 0.14 \\
1391 & In-plane O-H deformation of PEG & 0.02 & 0.12 \\
1119 & C-O-C asymmetric & 0.05 & 0.14 \\
1070 & Cluster of Al ${ }^{3+}$ and $\mathrm{O}^{2-}$ ions on the & 0.03 & 0.12 \\
& surface of alumina & 0.09 & 0.13 \\
\hline
\end{tabular}

of $\mathrm{Al}$; one can suggest that the most pronounced effect of treating alumina with $\mathrm{NaCl}$ is the decrease of the intensity and area of the $-\mathrm{OH}$ band located at $3566 \mathrm{~cm}^{-1}$, that is, the band characteristic of the surface $\mathrm{OH}$ and the formation of sodium aluminate [19]. Alkali metal modification of alumina surface after calcinations has a pronounced effect of decreasing the intensity and area of the $-\mathrm{OH}$ band compared with that on the parent alumina. 


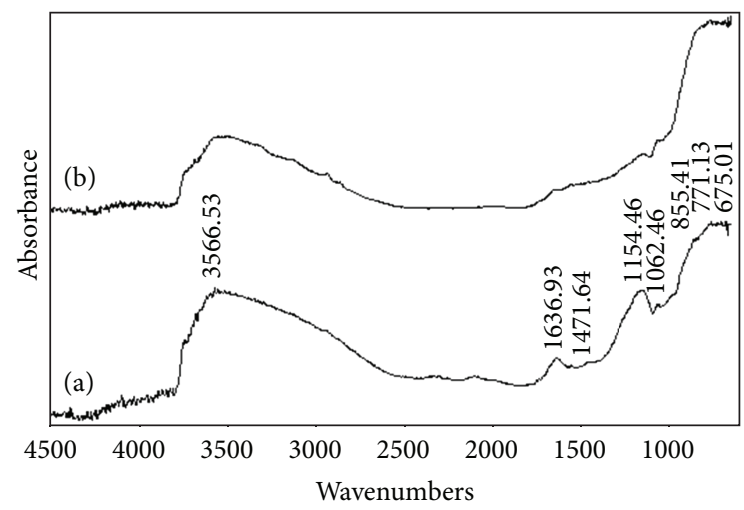

FIGURE 2: DRIFT spectra of (a) $\mathrm{Al}_{\mathrm{Na}}$ and (b) $\mathrm{Al}_{\mathrm{CNa}}$.

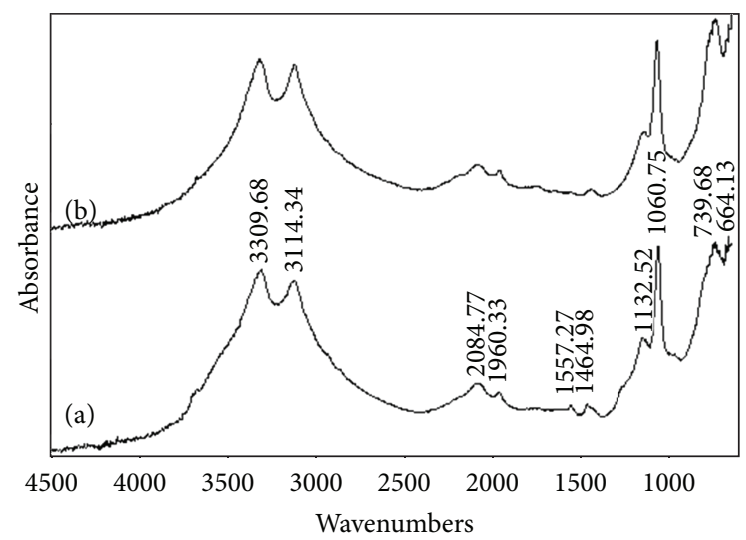

FIgURE 3: DRIFT spectra of (a) $\mathrm{Al}_{\mathrm{HT}}$ and (b) $\mathrm{Al}_{\mathrm{CHT}}$.

DRIFT spectra of $\mathrm{Al}_{\mathrm{HT}}$ and $\mathrm{Al}_{\mathrm{CHT}}$ are shown in Figure 3 and the bands assignment are illustrated in Table 4. From this data we can conclude that the $-\mathrm{OH}$ band at 3334 and $3504 \mathrm{~cm}^{-1}$ in $\mathrm{Al}$ and $\mathrm{Al}_{\mathrm{C}}$ respectively, was shifted and split into two bands at 3309 and, $3114 \mathrm{~cm}^{-1}$ in $\mathrm{Al}_{\mathrm{HT}}$ and $\mathrm{Al}_{\mathrm{CHT}}$; this is in agreement with the data reported by Ponthieu et al. [20], who attributed this to the formation of crystalline boehmite. The intensity of band at $1060 \mathrm{~cm}^{-1}$ which is assigned to cluster of $\mathrm{Al}^{3+}$ and $\mathrm{O}^{2-}$ ions on the surface of alumina was increased.

Figure 4 and Table 5 show DRIFT spectra of $\mathrm{Al}_{\mathrm{CCo} 10 \%}$ and $\mathrm{Al}_{\mathrm{CBO} 10 \%}$ together with that of $\mathrm{Al}_{\mathrm{C} 1000}$ for the subject of comparison. It is observed that the band located at $3467 \mathrm{~cm}^{-1}$ in the spectrogram of $\mathrm{Al}_{\mathrm{CCo1} 1 \%}$ and $\mathrm{Al}_{\mathrm{CBo10} \%}$ corresponds to the band located at $3504 \mathrm{~cm}^{-1}$ in the spectra of $\mathrm{Al}_{\mathrm{C}}$ (Figure 4). The shift to low wave number could be attributed to the interaction with the polymer (PEG). The interaction of PEG with alumina takes place presumably through $\mathrm{H}$-bonding between the ethoxy group of the polymer and the hydroxylated alumina [18]. The band located at $1633 \mathrm{~cm}^{-1}$ in $\mathrm{Al}_{\mathrm{C}}$ due to scissoring of two -OH bands from the moisture is shifted to $1616 \mathrm{~cm}^{-1}$ and overlapped with PEG band at $1729 \mathrm{~cm}^{-1}$ as shown in spectrogram of $\mathrm{Al}_{\mathrm{CCo10} \%}$ and $\mathrm{Al}_{\mathrm{CBo10} \%}$. Also new bands at 2925 and $2850 \mathrm{~cm}^{-1}$ due to $\mathrm{CH}_{2}$ symmetrical stretching vibrations and bands at $1460 \mathrm{~cm}^{-1}$ due to in-plane

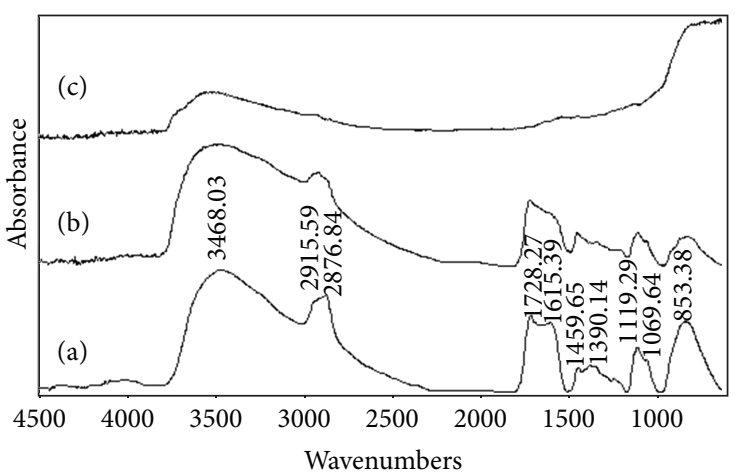

FIGURE 4: DRIFT spectra of (a) $\mathrm{Al}_{\mathrm{CCo10 \%}}$, (b) $\mathrm{Al}_{\mathrm{CBo} 10 \%}$, and (c) $\mathrm{Al}_{\mathrm{C} 1000}$.

scissoring of $\mathrm{CH}_{2}$ group are shown. The band at $1390 \mathrm{~cm}^{-1}$ was assigned to in-plane $\mathrm{O}-\mathrm{H}$ deformation of PEG. The band at $1119 \mathrm{~cm}^{-1}$ corresponding to $\mathrm{C}-\mathrm{O}-\mathrm{C}$ asymmetric stretching frequency also was observed due to interaction of alumina surface with polymer. The band at $877 \mathrm{~cm}^{-1}$ due to $\mathrm{Al}-\mathrm{O}$ stretching of $\mathrm{Al}_{2} \mathrm{O}_{3}$ is intensified and shifted to $853 \mathrm{~cm}^{-1}$ after interaction with PEG.

\section{Conclusion}

(i) The characterization of the alumina as solid support and/or solid stationary phase using DRIFT spectroscopy is of prime importance not only for determining the structure, textural, and surface chemistry of the phase but also for understanding how modification is related to the changes in these properties and also to the change in the performance of the stationary phase.

(ii) The FTIR bands of hydroxyl groups of calcined alumina was shifted to $3504 \mathrm{~cm}^{-1}$, and exhibit decrease in its intensity as the calcination temperature increases which is attributed to partial dehydroxylation and the formation of crystalline boehmite.

(iii) The most pronounced effect of treating alumina with $\mathrm{NaCl}$ is the decrease of the intensity and area of the $-\mathrm{OH}$ band located at $3566 \mathrm{~cm}^{-1}$, due to the formation of sodium aluminate. Alkali metal modification of alumina surface after calcinations has a pronounced effect of decreasing the intensity and area of the ($\mathrm{OH}$ ) band compared with that on the parent alumina due to the summation effect of calcinations and alkali metal treatment.

(iv) The interaction of PEG with alumina takes place presumably through $\mathrm{H}$-bonding between the ethoxy group of the polymer and the hydroxylated alumina leading to shift of hydroxyl band to low wave number.

(v) DRIFT spectroscopy represents the strength and abundance of surface acidic $\mathrm{OH}$ which determine the adsorption properties of polar and nonpolar sorbents. Generally, all treated samples exhibit decrease of $\mathrm{OH}$ 
groups compared with those of parent ones and the drastic decrease was observed upon calcination at $1000^{\circ} \mathrm{C}$.

\section{References}

[1] K. Naito and S. Takei, "Adsorption effects in gas-liquid partition chromatography. Quantitative evaluation," Journal of Chromatography A, vol. 190, no. 1, pp. 21-34, 1980.

[2] K. Naito, H. Ogawa, S. Moriguchi, and S. Takei, "Adsorption effects in gas-liquid chromatography: solute retention in the hydrocarbon solute-polar liquid stationary phase (triton $\mathrm{x}-100$ ) system," Journal of Chromatography A, vol. 299, pp. 73-85, 1984.

[3] A. M. Elfadly, U. F. Kandil, A. Y. El-Naggar, M. A. Ebied, and R. M. Abdrabou, "Preparation of polysiloxane nano-particles containing surface reactive groups for further functionalization," International Journal of Chemical Sciences, vol. 11, no. 1, pp. 372382, 2013

[4] S. Faramawy, A. M. El-Fadly, A. Y. El-Naggar, and A. M. Youssef, "Surface-modified silica gels as solid stationary phases in gas chromatography," Surface and Coatings Technology, vol. 90, no. 1-2, pp. 53-63, 1997.

[5] J. H. de Boer, "Constitution and properties of silica-aluminacatalysts," Discussions of the Faraday Society, vol. 52, pp. 109-112, 1971.

[6] R. Leboda, E. Mendyk, A. Gierak, and V. A. Tertykh, "Hydrothermal modification of silica gels (xerogels) 1. Effect of treatment temperature on their porous structure," Colloids and Surfaces A, vol. 105, no. 2-3, pp. 181-189, 1995.

[7] A. P. Legrand, The Surface Properties of Silicas, chapter 3, John Wiley \& Sons, New York, NY, USA, 1st edition, 1998.

[8] V. M. Gun'ko, J. Skubiszewska-Zieba, R. Leboda, and V. V. Turov, "Impact of thermal and hydrothermal treatments on structural characteristics of silica gel Si-40 and carbon/silica gel adsorbents," Colloids and Surfaces A, vol. 235, no. 1-3, pp. 101111, 2004.

[9] S. V. Slavov, K. T. Chuang, and A. R. Sanger, "Modification of $\gamma$-alumina with chlorotrimethylsilane," Journal of Physical Chemistry, vol. 99, no. 46, pp. 17019-17027, 1995.

[10] S. V. Slavov, A. R. Sanger, and K. T. Chuang, "Mechanism of silation of alumina with hexamethyldisilazane," Journal of Physical Chemistry B, vol. 102, no. 28, pp. 5475-5482, 1998.

[11] S. V. Slavov, K. T. Chuang, and A. R. Sanger, "Methane elimination during silation of partially dehydroxylated $\gamma$-alumina," Langmuir, vol. 11, no. 10, pp. 3607-3609, 1995.

[12] M. M. Kopecni, S. K. Milonjic, and R. J. laub, "Gas-solid chromatographic properties of alkali-metal modified silica," Analytical Chemistry, vol. 52, pp. 1032-1035, 1980.

[13] S. Moriguchi, K. Naito, and S. Take, "Characterization of modified alumina as an adsorbent for gas-solid chromatography: modification of alumina with alkali-metal fluorides," Journal of Chromatography A, vol. 131, pp. 19-29, 1977.

[14] A. V. Kiselev, N. V. Kovaleva, and Y. S. Nikitin, "Gas chromatography on monolayers," Journal of Chromatography A, vol. 58, pp. 19-30, 1971.

[15] A. Di Corcia, A. Liberti, and R. Samperi, "Gas-liquid-solid chromatography-theoretical aspects and analysis of polar compounds," Analytical Chemistry, vol. 45, no. 7, pp. 1228-1235, 1973.

[16] A. A. Walter and M. D. Marek, "Preparation of diatomaceous surfaces for the synthesis of bonded phases and trace analysis," Journal of Chromatography A, vol. 111, pp. 37-41, 1975.
[17] L. W. Wray and F. M. Robert, "Laboratory preparation and applications of modified carbowax 20M bonded supports to the gas chromatography of pesticides," Journal of Chromatography A, vol. 153, pp. 409-421, 1978.

[18] L. Saravanan and S. Subramanian, "Surface chemical studies on the competitive adsorption of poly(ethylene glycol) and ammonium poly(methacrylate) onto alumina," Journal of Colloid and Interface Science, vol. 284, no. 2, pp. 363-377, 2005.

[19] A. Fukazawa, S. Moriguchi, K. Naito, and S. Takel, "Characterization of modified alumina as an adsorbent for gas-solid chromatography: modification of alumina with alkali metal chloride," Journal of Chromatography A, vol. 295, pp. 63-71, 1984.

[20] E. Ponthieu, E. Payen, G. M. Pajonk, and J. Grimblot, "Comparison of drying procedures for the preparation of Alumina powders with the system Al-Alkoxide/Tertiary Butanol/Water," Journal of Sol-Gel Science and Technology, vol. 8, no. 1-3, pp. 201206, 1997. 

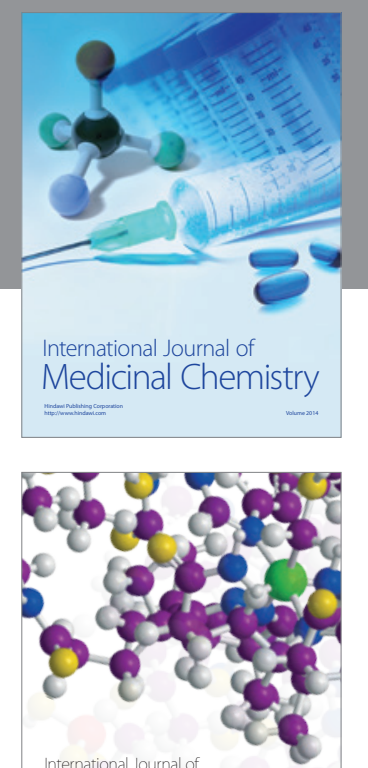

\section{Carbohydrate} Chemistry

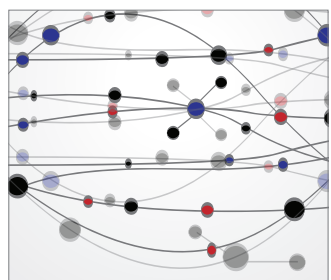

The Scientific World Journal
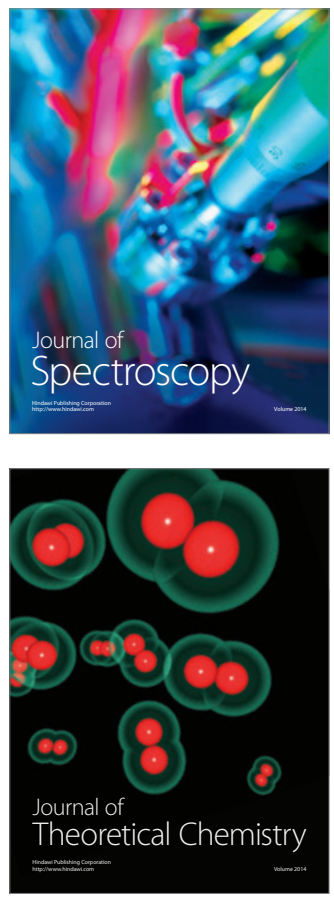
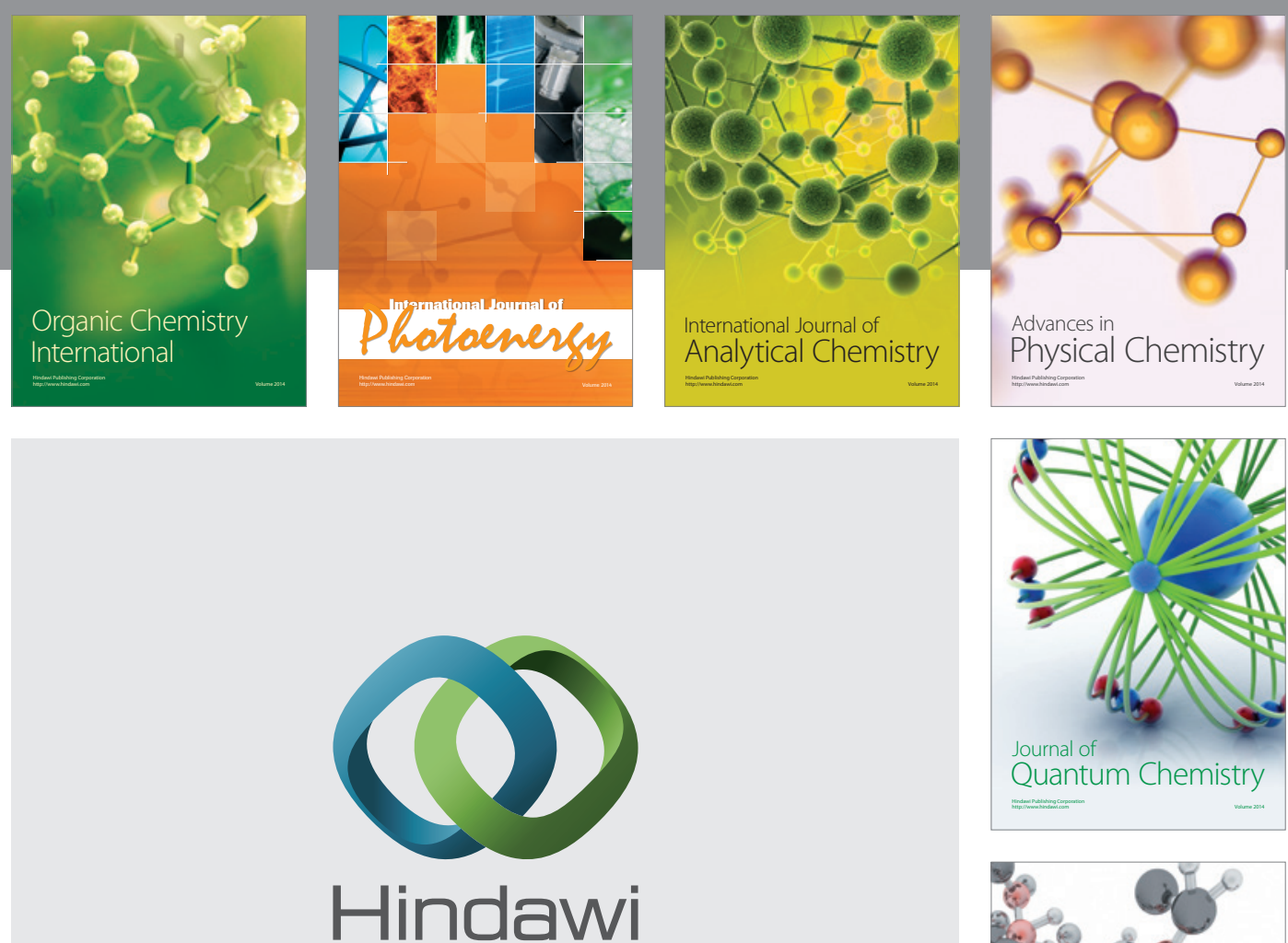

Submit your manuscripts at

http://www.hindawi.com

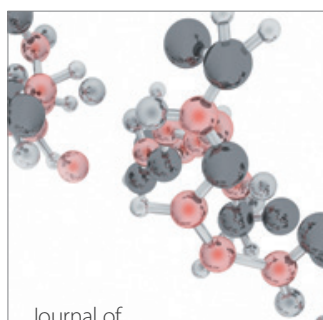

Analytical Methods

in Chemistry

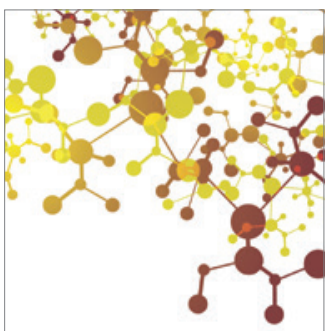

Journal of

Applied Chemistry

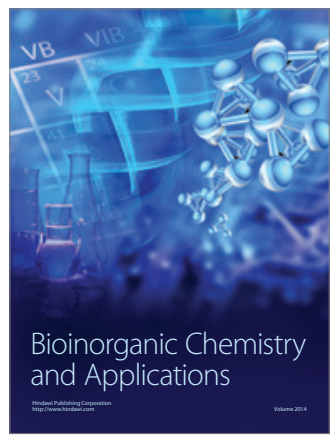

Inorganic Chemistry
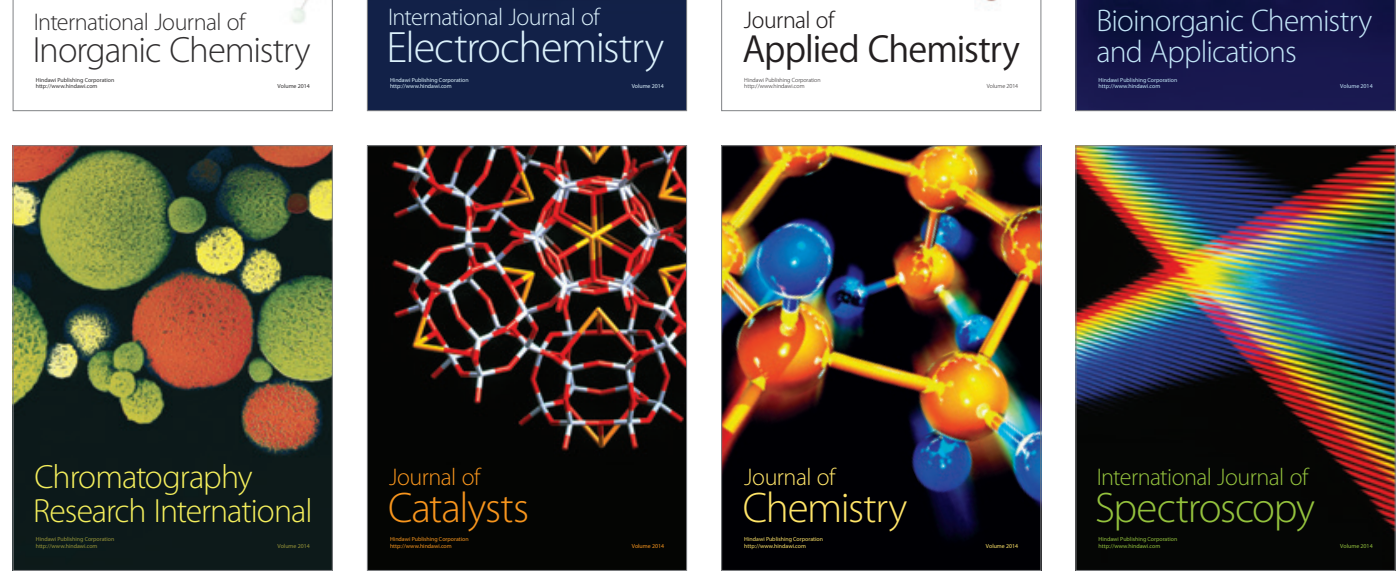